\title{
STUDY IN POSSIBILITIES OF PROFESSIONAL ORIENTATION IN TRAINING OF SPECIALISTS IN AGRARIAN AND TECHNICAL UNIVERSITIES
}

Stanislav Nikolaenko ${ }^{1}$, Oksana Bulgakova ${ }^{1}$, Valentina Vasileva ${ }^{2}$, Ilmars Dukulis ${ }^{3}$, Lesia Zbaravska ${ }^{4}$

${ }^{1}$ National University of Life and Environmental Sciences of Ukraine, Ukraine; ${ }^{2}$ University of Ruse Angel Kanchev, Bulgaria; ${ }^{3}$ Latvia University of Life Sciences and Technologies, Latvia; ${ }^{4}$ State

Agrarian and Engineering University in Podillia, Ukraine semjons@apollo.lv, ilmars.dukulis@1lu.lv

\begin{abstract}
The theoretical provisions, which form the basis of the concept of teaching physics to applicants for higher education in agrarian-technical educational institutions, are analyzed in the article. The main methods of implementing the professional orientation of teaching physics at lecture classes for applicants for higher education in agrarian-technical educational institutions have been revealed. The main ways of increasing professional knowledge of applicants for higher education in the physics course were determined. The tested methodology of implementing the professional orientation of teaching physics at lectures in universities was described. To identify the level of physics training of engineering applicants for higher education we conducted an experimental study, which showed that the course of physics in the higher agrarian and technical educational institution has transformed from a fundamental to a general educational subject. Students are not aware of the purpose of learning physics as the foundation of future professional activity, they cannot transform the knowledge obtained in physics classes to the disciplines of professional and practical training and the general technical cycle, as well as in the course works and diploma design. The above-mentioned facts allow drawing a conclusion about the necessity of interconnection between the principles of fundamentality and professional orientation in teaching physics to applicants for higher education at agrarian-technical educational institutions. It is proved that the use of professionally directed material contributes to the formation of the physical knowledge system of applicants for higher education, the acquisition of various practical skills and abilities, stimulates cognitive interest in the study of physics as a science, allows to better absorb the material of other disciplines of the natural sciences cycle, develop their cognitive and creative abilities, affect the formation of strong motives for obtaining knowledge in special disciplines.
\end{abstract}

Keywords: physics, lecture, professional orientation, component.

\section{Introduction}

One of the main objectives of higher education is formation of professional competence of a graduate, providing an ideal end result, i.e. training such a specialist, who would master the necessary knowledge, abilities, skills of creative activity, has an appropriate outlook and erudition, intellectual level, acquired self-education skills, who has formed professional qualities, moral, aesthetic, environmental culture.

The main purpose of the system of higher education of agrarian and technical educational institutions is to train qualified specialists in accordance with the social order. Modern agro-industrial industry, which uses complex technologies, needs young specialists able to assimilate and perceive modern technology. In turn, society demands from the system of agrarian education training of future specialists with a high level of technical training, developed physical and technical thinking. Therefore, it is the professional activity of specialists that sets and defines the purpose of teaching all academic disciplines, including the course of physics as the basis of fundamental scientific training of engineers.

In the modern model of agro-industrial specialists' formation the professional orientation of physics training becomes more and more important. Quality training of agricultural engineers contributes to the fastest perception of modern technology, provides professional mobility of engineers, in the conditions of competition in the labor market it becomes urgent.

To address this issue researchers performed a number of studies on the formation of professional competence, revealed its basic principles and importance in the training of future specialists [1-4]. Researchers in their works focus on the professional training of masters in international affairs [5], border service students [6], medical physicists [7], and future agricultural production specialists [8], using an interdisciplinary approach.

It should be noted that competence has been studied by such researchers as G. Hall, M. Mulder, T. Hyland, D. Clelland, J. Raven, W. Rothwell, G. Ryle, D. Kaittani, V. Derri, E. Kioumourtzoglou and others. In particular, J. Raven considers competence as a specific ability required to effectively perform 
a specific action in a specific subject area, including highly specialized knowledge, specific subject skills, ways of thinking, as well as understanding the responsibility for one's actions [9]. Mulder M. studies the concept and practice of professional and practical learning, including related research traditions and educational positions [10].

Studies $[11 ; 12]$ focus on interdisciplinarity as an approach to teaching and learning. They not only include materials from various disciplines, but also focus on theoretical and practical work in physics.

At the same time, there are still no studies devoted to a comprehensive approach to the problem of training quality of engineering applicants in higher education, taking into account their future professional activities.

The study of literary sources, normative-legal acts, plans and programs, standards for engineering training areas, educational and qualification characteristics, the analysis of experience in conducting classes in physics and the implementation of the pedagogical experiment allowed us to identify the following:

- the discrepancy between the content of the new standards of education and outdated educational, instructional and normative support and pedagogical approaches;

- insufficient implementation of the principle of professional orientation in teaching physics to students of agrarian-technical universities;

- the need for students to assimilate a huge amount of teaching material and the systematic reduction of the number of hours to study physics.

As a result, a significant number of students are not clearly aware of the purpose of studying physics. During the study of physics they do not sufficiently acquire the fundamental knowledge of physics and the ability to apply it to implementation of tasks related to future professional activities [13].

The purpose of the study - determination of the basic principles of forming professional competence as a dominant condition for improving the quality of training of future specialists of agrarian and technical educational institutions.

\section{Materials and methods}

To achieve the goal, we used the following research methods: theoretical analysis of philosophical, psychological and pedagogical literature on the topic of the research in order to select and comprehend the factual material; analysis of concepts, theories and techniques has the aim to identify ways to solve the problem under study as close to the future professional activity of higher education applicants. One of the necessary conditions for the professional training of future specialists is the professional orientation of training. We believe that to solve this problem it is necessary to carry out an in-depth analysis of the interrelation of the general physics course with the main general technical and professional, and practical training disciplines. Firstly, it will allow to define, which physical knowledge, abilities and skills will be used in further professional training of applicants for higher education, secondly, it will allow to use most skillfully at the lessons of physics the examples of agrotechnical content, connected with the future professional activity of applicants for higher education. Studying the disciplines of specialization at a later stage does not create an incentive in the teaching of natural science and general technical disciplines. Knowledge on fundamental, general technical and general theoretical disciplines is not quickly applied during a long period of study, it remains a heavy baggage of knowledge, as it begins to be applied in an incomplete volume during the study of special profile disciplines at the last courses. In order to create a solid theoretical base, we analyzed the links of physics with the main general technical, practical and professional training disciplines. For example, the study of such general technical discipline as "Theoretical Mechanics" is based mainly on the kinematics and dynamics of a material point, studied in the course of physics. The study of "Hydraulics" and "Heat Engineering" is based on molecular physics (properties of liquids, gases, isoprocesses, transfer phenomena, etc.). The course "Material Engineering" is based on the topics "Rotation of a Solid Body Around a Stationary Axis" (moment of force, moment of inertia, basic law of dynamics for rotational motion, etc.) and "Elastic Forces" (deformation, relative and absolute elongation, etc.) already studied in physics. The section "Electricity and Magnetism" of the physics course is the basis for the study of the discipline "Electrical Engineering". The study of disciplines of professional and practical training is also interconnected with the sections and specific topics of the physics course. Thus, the study of special 
disciplines "Agricultural machinery" and "Technology of agricultural production" is impossible without knowledge of such topics of physics course as "Kinematics", "Dynamics" and "Elastic forces".

During the experiment the following tasks were solved: 1) To identify the level of preparation of applicants for higher education in physicse; 2) To check how much the traditional system of teaching physics contributes to preparation of applicants for higher education to study general technical and special disciplines; 3) To identify the shortcomings of the existing methodology of training applicants for higher education of agrarian and technical schools in physics. The following research methods were used: survey of applicants for higher education to identify their understanding of the importance of studying physics for future professional activities; survey of applicants for higher education to identify the ability to apply knowledge of physics to solve specific professional problems.

Students of the 1st and 2nd years of the National University of Bioresources and Nature Management of Ukraine, specialty "Agroengineering", "Agronomy" (a total of 300 higher education applicants and 6 teachers), as well as the 1st-5th years of the Podolsk State Agrarian and Technical University (a total of 200 higher education applicants and 6 teachers) took part in the experiment.

In order to determine the content of professionally-oriented material and its importance in the study of physics, we analyzed the content of general technical disciplines and disciplines of professional and practical training, the questionnaire survey of applicants for higher education 2-5 courses ( 150 applicants for higher education and 8 teachers). The questionnaire of higher education applicants to identify the content of professionally oriented material in physics included the following questions.

1. What is the place of physics in your future profession?

2. Does the physics course give you a basis for studying special disciplines?

3 . What place do you give to physics in solving professional problems?

4. Does your knowledge of physics help you in preparing your term and graduation theses?

5 . Does studying physics increase your intellectual potential?

6. Does physics teach you how to "think" logically?

7. Does physics shape creative thinking?

8. Does the study of physics contribute to the professional training of an agricultural engineer?

9. Without knowledge and skills in physics, is academic and research work in the specialty possible?

\section{Results and discussion}

When constructing the content of the physics course, an important link is the use of professionally directed tasks [14]. These physics tasks should meet the following requirements:

- make sure there is a close connection to real professional tasks;

- take into account interdisciplinary links of the physics course with disciplines of professional and practical training;

- provide for a gradual increase in the complexity of tasks;

- require a variety of mental activities;

- provide cognitive activity of higher education applicants;

- contribute to the formation of applicants for higher education of some professional activities.

The close connection of tasks with real professional tasks involves the choice of both objects that are analyzed and agricultural processes that students will deal with in practice, for example, the calculation of the kinematic and dynamic characteristics of agricultural machinery and their mechanisms. The use of modern physical methods in agronomy makes it possible to improve the diagnosis and regulation of crop yields, thereby helping to increase their yields and productivity. The solution of professionally directed tasks contributes to a deep understanding of the physical essence of the processes occurring in nature, agricultural machines, mechanisms, devices.

For example, for applicants for higher education in "Agroengineering" tasks were selected that contain elements of professional direction in their future professional activity [14]:

- the central conveyor belt of the KTU-10 feeder wagon performs two movements simultaneously: forward together with the combine at a speed of $7.92 \mathrm{~km} \cdot \mathrm{h}^{-1}$ and moving backward relative to the harvester at a speed of $1.4 \mathrm{~m} \cdot \mathrm{s}^{-1}$. Determine the velocity of the transporter points relative to the field (Fig. 1). 
- the transporter of the tilt chamber of the KZS-9 combine moves at a speed of $3.2 \mathrm{~m} \cdot \mathrm{s}^{-1}$. What path will the conveyor bar take during one hour of combine operation (Fig. 2)?

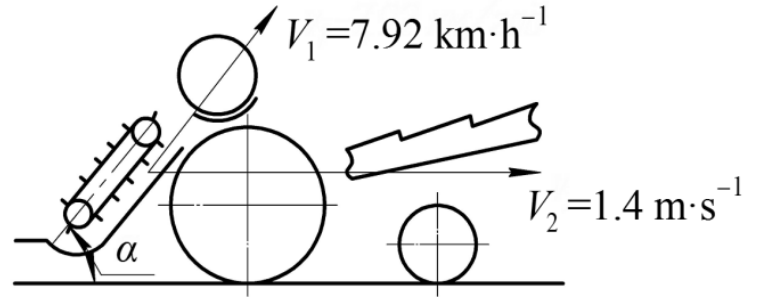

Fig. 1. Movement diagram of KTU-10 feeder wagon

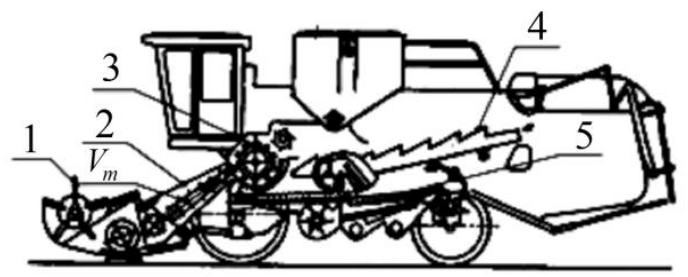

Fig. 2. Scheme of grain harvester KZS-9:

1 - reel; 2 - inclined chamber conveyor;

3 - threshing device; 4 - straw walker;

5 - separating sieves

The tractor HTZ-2511 has a power of $22 \mathrm{~kW}$. Can this tractor pull in 3rd gear at forward speed $5.22 \mathrm{~km} \cdot \mathrm{h}^{-1}$ unit of two cultivators KPS-4 with a pulling capacity of $4100 \mathrm{~N}$ each and 8 harrows BZTS 1,0 with a pulling capacity of $880 \mathrm{~N}$ each (Fig. 3)?

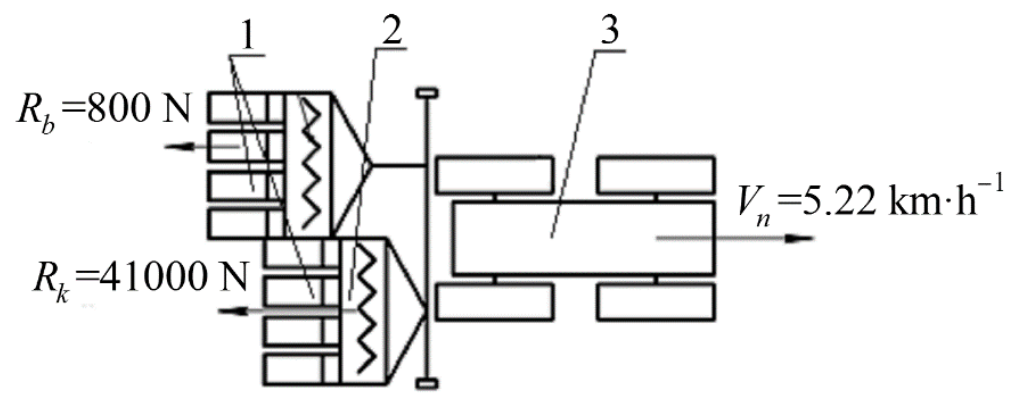

Fig. 3. Diagram of a tillage machine: 1 - harrows; 2 - cultivators; 3 - tractor

By solving such problems, students were convinced of the complexity of technological processes, the need for deep knowledge of physics in order to master the basics of agricultural production. Most of the problems were chosen so that their solutions would help overcome the difficulties that students encounter in the process of industrial practice, when studying the basics of agricultural production. Significant for problem solving were such tasks that created a "conflict situation". The attempt of higher education applicants to find the answer activates their thinking, draws their attention to the set task, causes increased interest [5]. When compiling tasks, it should be borne in mind that their conditions should reflect the information on various branches of local and regional production, on the prospects of their development, environmental problems arising in this process. The text of the tasks should contain only the most common production terms and concepts. The preference should be given to those tasks, the solution of which allows to rely on visual images: parts of machines and mechanisms. Moreover, the production material in their content should not cover the physical one, and while solving them, the role of physics in agriculture and its production problems should be shown, so that students realize that the knowledge received in physics classes will help them in future master the chosen specialty, to work successfully in agricultural production.

Interdisciplinary links of the physics course with disciplines of professional and practical training had anticipatory and prospective character. The system included tasks which took into account both anticipatory and accompanying links of the physics course with such disciplines as: "Agricultural machinery", "Mechanical and technological properties of agricultural materials", "Material science", "Theoretical mechanics"; prospective links with the disciplines "Electrical engineering", "Energy facilities for agroindustrial complex", "Soil science", "Agrometeorology", etc. Solving problems of interdisciplinary nature stimulates cognitive interest in the study of physics as a science, and also allows to better absorb the material of other disciplines of the natural sciences cycle, develops the cognitive and creative abilities, affects formation of strong motives for obtaining knowledge in special disciplines. Gradual complication of the nature of the tasks was provided by the structure of the educational process. 
If we consider lectures as an orientation stage of the learning process, and practical and laboratory classes as an executive (training) stage, then accordingly the purpose of the lecture course tasks is to orient higher education applicants in theoretical material, illustrate concepts studied by examples of agricultural objects, search for physical regularities underlying their functioning. In a lecture course, apart from the presentation of the educational material, a task was set to orient the student to the main directions of future professional activity, conditions were created for projecting the laws of physics to the tasks related to future professional activity. At the same time, students were shown the ways of performance of such tasks, in other cases a problem was put, which was solved in the process of independent work. Tasks for independent work were formed as complex tasks on an example of professional objects. For example, at the lectures for candidates for higher education in "Agroengineering", when studying the topic "Kinematics" the definition of "trajectory" was given, with the emphasis on the fact that in agriculture determining the trajectory of moving parts, machine units, agricultural products is important in each individual case: research, calculation and design, design or technological issues.

In studying this topic, students were offered professionally-oriented tasks, in particular to determine:

- the trajectory of the reel bar of grain harvesters depending on the ratio of the machine speed to the speed of the bar (affects the quality of harvesting);

- friction coefficients of surfaces and materials (without this knowledge it is impossible to design a single agricultural machine);

- theoretical presentation of the material was illustrated not only with the help of abstract diagrams, but also with the help of technical ones, for example, the movement of not just an abstract material point, but a point located on the rotating drum of the combine harvester reel [14] (Fig. 4).

The tasks included in the methodological system required different levels of mental activity and were constantly becoming more and more complicated. Tasks of professional content, as they are connected with the application of knowledge in the direction of training of the future specialist of agrarian and technical sphere, provide realization of a part of productive activity. In this case the maximum cognitive activity of applicants for higher education was provided. Productive activity was characterized by the fact that in the process of its performance new knowledge or ways of action are acquired, first of all, at performance of tasks of search-cognitive, research or creative character.

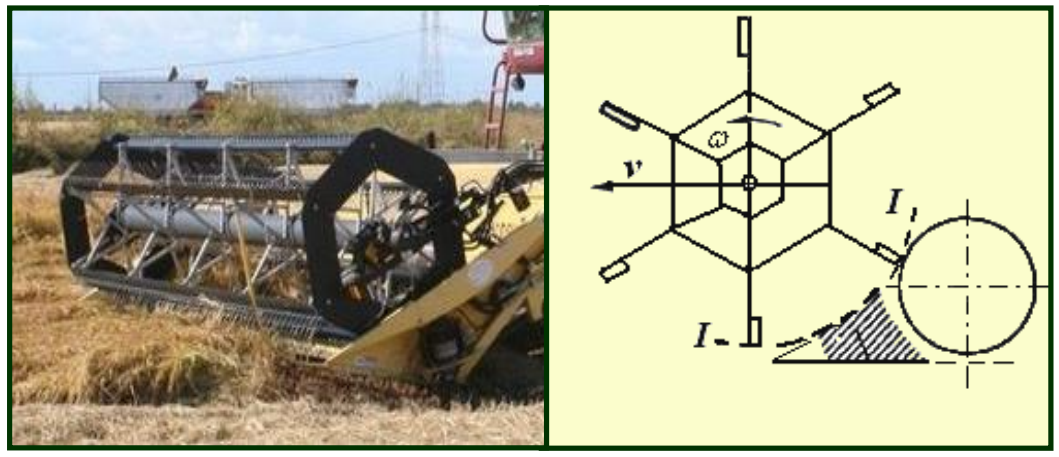

Fig. 4. Computer model of movement of the reel of a combine harvester

Search and cognitive tasks were formed in such a way that the student in the recommended literature and lecture course could not find a direct answer to the question posed. He was faced with the need to search, evaluate, and generalize. While doing this type of tasks, students independently acquired new knowledge, applied it in future professional situations, mastered professional skills. Tasks of research character assumed a high level of mental activity, they required from the student research. Examples of this type of tasks were the following:

- how harmonic vibrations of machine parts affect the movement and operation of the machinetractor unit as a whole;

- determine the effect of the friction coefficient, the angle of inclination of the surface on the speed of grain movement in the combine harvester's loading bunker. 
Professionally-oriented tasks of a creative nature were used mainly for term and diploma projects and papers, during which students independently applied their knowledge of physics to perform production tasks. One of the tasks of training in higher agrarian-technical institution is to form an active creative personality. This was facilitated both by the content of the tasks, and the use of various techniques of activation of cognitive activity of applicants for higher education. Tasks of productive character turn out to be learning problems for applicants of higher education, as they put them before the necessity to obtain new knowledge and to apply it in a new situation, to master new ways of action. Successful study of physics in combination with training workshops contributes to the formation of technical competence of future specialists. To identify the level of training of applicants for higher education of agrarian-technical universities in physics we conducted a pedagogical experiment. As a rule, students consider that the physics course at agrarian-technical university has general educational character and does not play a significant role for studying special disciplines. At the examinations for general technical disciplines, more than $60 \%$ of applicants for higher education link courses of general technical disciplines ("Electrical Engineering", "Theoretical Mechanics", "Machine Parts") with questions on physics, and in such disciplines as "Mechanism and Machine Theory", "Mechanics of Materials and Constructions", there is no connection with the course of physics at all. Examinations in professional disciplines showed that, while studying the disciplines of professional and practical training, the student has almost no reference to the questions and laws of physics, that is, more than $87 \%$ of applicants to higher education do not connect physics and the disciplines of professional and practical training. At the same time, a survey of applicants for higher education was conducted to identify those activities that would improve the level of professional training of applicants for higher education of agrarian and technical universities. The research covered 151 students of "Agroengineering" specialty of the National University of Life and Environmental Sciences of Ukraine (NUBiP), the Nizhyn Agrotechnical Institute (NATI) and the D. Motorny Tavrichesky State Agrotechnological University (TSATU).

To the question "What should be done to improve the level of professional training of applicants for higher education in the study of physics," students responded as follows:

- "to improve the material and technical support of the educational process" (15.2\% of all interviewed applicants for higher education, including: NUBiP $-19.3 \%$, NATI $-3.7 \%$, TSATU $-6.7 \%)$;

- "change the methodology of teaching" (23.8\% of higher education applicants, including: NUBiP $-15.6 \%$, NATI $-48.2 \%$, TSATU $-40 \%$ );

- "introduction of elements of professional orientation in various types of educational activities in physics" (21.9\% of applicants for higher education, including: NUBiP $-25.7 \%$, NATI $11.1 \%$, TSATU $-13.3 \%$ );

- "increase the number of hours to study physics" (17.9\% of higher education applicants, including: NUBiP $-16.5 \%$, NATI - 25.9\%, TSATU - 13.3\%);

- "increase the level of professional training of researchers (teachers)" (13.9\% of applicants for higher education, including: NUBiP $-13.8 \%$, NATI $-11.1 \%$, TSATU $-20 \%$ );

- "develop the ability to work independently" (3.3\% of applicants for higher education, among them: NUBiP - 3.7\%, NATI- no student offered this option, TSATU-6.7\%);

- six higher education applicants offered their answer: use of the latest information technology in the study of professionally oriented material.

The results of a survey of applicants to universities NUBiP, NATI and TGATU are presented in Fig. 5. According to the results of the study, there is a reason to believe that: the majority of applicants for higher education do not see the relationship between physics, general technical disciplines and disciplines of professional and practical training; The content of lectures and practical classes includes abstract material, and laboratory work does not differ in any way from the work carried out, for example, in a pedagogical university.

In Fig. 5 digits show the following answers.

1. To improve the material and technical support of the educational process.

2. Change the way physics is taught. 
3. Introduction of elements of professional orientation in various types of educational activities in physics.

4. Increase the number of hours spent studying physics.

5. Raising the level of professional training of scientists.

6. To develop the ability of applicants for higher education to work independently.

7. Your option.

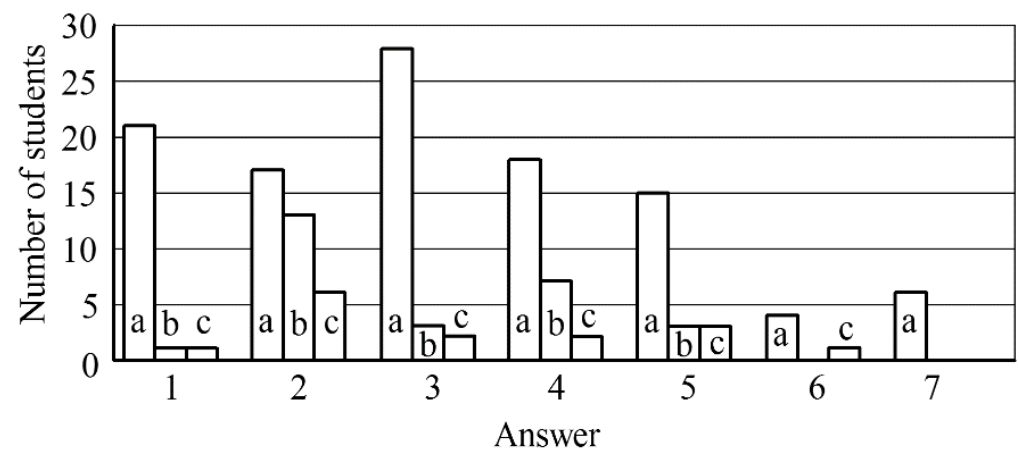

Fig. 5. Ways to improve professional preparation of applicants for higher education in study of physics: a - NUBiP; $b$ - NATI; c - TSATU

The decisive criterion for the effectiveness of the proposed methodological support should be considered the learning outcomes, which show the impact of the knowledge obtained in study of physics on the level of study of special disciplines "Mechanical and technological properties of agricultural materials", "Agricultural machinery" "Hydraulics and water supply" and other professional disciplines, development of future specialists in creative, analytical thinking.

For this purpose, the achievement of students in the control and experimental groups in these disciplines was compared by the results of examinations. The total number of students in the control and experimental groups is 260. Comparison of academic performance in the disciplines "Agricultural machinery", "Mechanical and technological properties of agricultural materials", "Hydraulics and water supply" suggests that it is higher in the experimental groups than in the control groups. Feedback from teachers, who conducted classes in special disciplines, indicates that students in the experimental groups use the connection of physics with professionally-oriented disciplines to a greater extent. Analyzing the results of the experiment, we can conclude that the students of higher agrarian and technical educational institutions, who studied using the proposed educational and methodological support, formed deep fundamental knowledge and skills, that is, they are able to project their knowledge of physics to the disciplines of the professional and practical cycle.

Based on the results we came to the following conclusions:

- the majority of applicants to higher education do not see the relationship between physics, general technical disciplines and disciplines of professional and practical training;

- the content of lectures and practical classes includes abstract material, and the laboratory work is not different from the work carried out, for example, in the pedagogical university;

- the reasons for this situation are the insufficiently formed physics program (taking into account the direction of training); the traditional system of teaching physics at agrarian and technical university does not contribute sufficiently to the implementation of professional orientation of training, does not allow significantly affect the professional development of applicants for higher education.

The results of the experiment found that training in the developed methodology contributes:

- increases the level of fundamental and professionally oriented knowledge of physics by 10$15 \%$;

- application of fundamental knowledge of physics to solve problems related to future activities and in the study of disciplines of professional and practical training increased by 25 .

In addition, the experiment showed that students, who studied the developed educational and methodological support of professionally directed course of physics, more actively used the knowledge 
of physics in the study of disciplines of professional and practical cycle, as well as took an active part in research work.

\section{Conclusions}

1. The use of interdisciplinary links and applied physical tasks in the educational process will create a holistic and systematic view of the structure and content of the physics course and its importance for future professional activities; purposefully form the initial professional knowledge, skills and abilities in the study of physics.

2. The analysis of the results of the experiments showed that the average academic performance in the experimental group in physics increased by $15.02 \%$, the quality of knowledge by $33.89 \%$; in technical disciplines - success in the experimental group increased by $3.4 \%$, the quality of knowledge by $11.82 \%$.

3. An increase in the level of knowledge of students and in the levels of motivation and professional orientation testifies to the effectiveness and pedagogical feasibility of the proposed methodological foundations for organizing the professionally oriented activity of students in physics.

\section{References}

[1] Nikolaenko S., Bondar M., Bulgakova O., Dukulis I. Investigation of pedagogical conditions for development of professional self-perfection skills of future agricultural engineers. Engineering for Rural Development, Vol.19, 2020, pp. pp. 1364-1372.

[2] Nikolaenko S., Bondar M., Bulgakova O., Vartukapteinis K. Possibilities to control students' knowledge while trained for their future occupation in field of agricultural engineering. Engineering for Rural Development, Vol.19, 2020, art. 336.

[3] Zbaravska L., Chaikovska O, Semenyshena, R., Duhanets V. Interdisciplinary approach to teaching physics to students majoring in agrarian engineering and agronomy. Independent journal of management \& production. Vol.10 (7), 2019, pp. 645-657.

[4] Хуторской А. В. Педагогическая инноватика: методология, теория, практика (Pedagogical innovation: methodology, theory, practice). Moscow, 2005, 222 p. (In Russian)

[5] Zbaravska L., Slobodyan S. Interdisciplinary communication in teaching physics for students of agricultural universities. Středoevropský věstnĺk pro vědu a výzkum (Central European journal for science and research). Praha, 2016, pp. 97-101.

[6] Horabik J. Wpływ właściwości mechanicznych ziarna psyenicz na roykład obciążenia żbiorniku (Influence of mechanical properties of grain on the distribution of reservoir load). Acta Agrophysica, Vol.1, 1994. (In Polish)

[7] Гурьев А.И. Статус межпредметных связей в системе современного образования (The status of interdisciplinary connections in the system of modern education). Наука и школа, № 2, 2002, pp. 41-45. (In Russian)

[8] Nowak J. Strat z polowe w produkcji siana i kisżonek (Field losses in hay and silage production). Acta Agrophysica, 2007. pp.144 (In Polish)

[9] Raven J. Recent research supporting a specific-motive based model of competence. Prague, 2020, $34 \mathrm{p}$.

[10] Mulder M., Billett S., Harteis C., Gruber H. Conceptions of Professional Competence. In: (Eds). International Handbook of Research in Professional and Practice-based Learning. Dordrecht: Springer, pp. 107-137, 2014. (in English)

[11] Kaittani D., Derri V., Kioumourtzoglou E. Interdisciplinary: a focus on physics and physical education. Sport Science, 2016, Vol. 9, pp. 22-28.

[12] Cheng X., Wu L.-Y. The affordances of teacher professional learning communities: A case study of a Chinese secondary school. Teaching and Teacher Education, Vol.58, 2016, pp. 54 -67.

[13] Lyall C., Bruce A., Tait J., Meagher L. Interdisciplinary Research Journeys: Practical Strategies for Capturing Creativity. London: Bloomsbury, 2011, 240 pp.

[14]Zbaravska L., Chaikovska O., Hutsol T., Slobodyan S., Dumanskyi O. Professional competence as a key factor in improving the quality of engineering education. Environment technology. Environment. Technology. Resources. Proceedings of the 12th International Scientific and Practical Conference. Volume III, 2019, Rezekne, Latvia, pp. 253-256. 